\begin{tabular}{ll|l}
\hline Bentham open & The Open Parasitology Journal \\
\hline CrossMark & Content list available at: www.benthamopen.com/TOPARAJ/ & DOI: $10.2174 / 1874421401806010032,2018,6,32-40$ \\
\hline
\end{tabular}

RESEARCH ARTICLE

\title{
Repellence Activity of Cymbopogon Citratus (DC) Extracts on Anopheles Mosquitoes using Swiss Albino Rat and Human Volunteer
}

\author{
Omoya Funmilola Oluyemi ${ }^{*}$, Adewumi Tunde Ayodele and Ajayi Kehinde Oluyemi \\ Department of Microbiology, Federal University of Technology, Akure, Ondo State, Nigeria
}

Received: May 30, 2018

Revised: July 17, 2018

Accepted: July 25, 2018

\begin{abstract}
:
Introduction:

Insect-transmitted disease remains a major source of illness and death worldwide. Anopheles stephensi and Anopheles culicifacies are the important vectors of malaria, malaria continues to be a major public health problem in the tropical world. This study is aimed at carrying out repellence activity of Cymbopogon citratus (Lemon grass) extracts on Anopheles mosquitoes using swiss albino rat and human volunteers.
\end{abstract}

\begin{abstract}
Methods:
Methanol, chloroform and water were used to extract the bioactive compounds of plant leaves, qualitative and quantitative phytochemical components of plant extracts were determined, twenty-five laboratory-reared 3 day old Anopheles mosquitoes which had been starved for 5 hours were used, extracts and the commercial insecticide N, N-diethyl-3-methylbenzamide (DEET) were applied topically on the skin of uncovered portions of the hand of the human volunteers and abdomen of swiss albino rat after the abdominal hairs has been shaved and the landing rate of mosquitoes were observed to calculate percentage repellency.
\end{abstract}

Results:

The result revealed that methanol extract had the highest percentage yield of $10.3 \%$, tannin and alkaloid were present in all extracts. DEET had $100 \%$ repellency to Anopheles mosquitoes on both human volunteers and rats for 300 minutes post application, in human volunteers, water, chloroform and methanol extracts, has percentage repellency reduced from $100 \%$ to $94 \%$ after 60 minutes, $100 \%$ to $94 \%$ after 120 minutes and $100 \%$ to $83 \%$ after 150 minutes post application respectively while in swiss albino rat, water, chloroform and methanol extracts, percentage repellency reduce from $100 \%$ to $87 \%$ after 90 minutes, $100 \%$ to $87 \% 150$ minutes and $100 \%$ to $90 \%$ after 180 minutes post application respectively.

\section{Conclusion:}

Methanol extracts of $C$. citratus leaves could be used for the development of topical cream that repels mosquitoes for effective control of malaria.

Keywords: Anopheles mosquitoes, Cymbopogon citratus, Extracts, Repellency, Malaria, Plasmodium.

\section{INTRODUCTION}

Malaria remains one of the most prevalent diseases in the tropical world. With 200 million to 450 million infections annually worldwide, it causes up to 2.7 million deaths including 1 child every $30 \mathrm{~s}$ [1]. Malaria is a mosquito-borne disease is caused by parasitic protozoans (a type of unicellular microorganism) of the genus Plasmodium. Five species of Plasmodium can infect and be transmitted by humans [2]. The vast majority of deaths are caused by $P$. falciparum, $P$. vivax, while $P$. ovale, and P. Malariae [3].

\footnotetext{
* Address correspondence to the author at the Department of Microbiology, Federal University of Technology, Akure, Ondo State, Nigeria, Tel: +2348033738650; E-mail: fomoya@yahoo.com
} 
Malaria is common in tropical and subtropical regions because rainfall, warm temperatures, and stagnant waters provide an environment ideal for mosquito larvae. The rainy season may be important in malaria transmission due to high biting populations. Commonly, the disease is transmitted by a bite from an infected female Anopheles mosquito, which introduces the organisms from its saliva into a person's circulatory system, parasites can also be transmitted by blood transfusions, although this is rare [4].

Prevention of malaria includes medications, mosquito elimination and prevention of mosquito bites [5]. The presence of malaria in an area requires a combination of high human population density, high anopheles mosquito population density and high rates of transmission from humans to mosquitoes and from mosquitoes to humans [6]. If any of these is lowered sufficiently, the parasite will eventually be eliminated from that area. Furthermore, disease transmission can be reduced by preventing mosquito bites by using mosquito nets and insect repellents, or with mosquito-control measures such as spraying insecticides and draining standing water [7].

Control of mosquitoes is something of utmost importance in the present day with rising number of mosquito borne illnesses. Chemical control using synthetic insecticides had been favorable so far because of their speedy action and easy application. Certain plant species containing essential oils have proved efficacy as larvicides, adulticides, ovicides and repellents against different species of mosquitoes [8]. Natural pesticides, especially those derived from plants are more promising in this aspect. Aromatic plants and their essential oils are very important sources of many compounds that are used in different respects. Most of the mosquito control programmed target the larval stage in their breeding sites with larvicides [9]. Personal protective measures including repellents are widely used to prevent the transmission of mosquito-borne diseases by minimizing the contact between humans and vectors [10].

Repellent properties of several leaves extracts appear to be associated with the presence of monoterpenoids and sesquiterpenes [11]. Monoterpenes such as a-pinene, limonene, terpinolene, citronellol, citronellal, camphor and thymol are common constituents of a number of leaves extracts and they have mosquito repellent activity [12, 13]. Cymbopogon citratus (lemon grass) is commonly used in teas, soups and curries. This plant has been widely recognized for its enthnobotanical and medicinal usefulness [14]. Hence this study aimed at studying the repellence activity of Cymbopogon citratus (Lemon grass) extracts on Anopheles mosquitoes using Swiss albino rat and human volunteers.

\section{MATERIALS AND METHODS}

\subsection{Collection of Plant Materials}

Leaves of Cymbopogon citratus were collected from South gate area of Federal University of Technology, Akure, Ondo State, Nigeria, into a clean sack. The leaves were well screened and the unwanted ones were removed before processing for extraction.

\subsection{Processing and Extraction of Cymbopogon Citratus}

The fresh leaves were air dried for four weeks in the absence of contaminations until fully crispy. The leaves were crushed and pounded using clean mortar and pestle and pulverized into fine powder by blender. The powdered leaves were kept in an airtight container to avoid the absorption of moisture. The powdered sample was soaked for 72 hours in $70 \%$ methanol, chloroform and aqueous water in the ratio $1: 10$ each $(300 \mathrm{~g}$ of the powdered sample in 3000 millimeter of $70 \%$ methanol, chloroform and water) as solvents to extract the bioactive compounds, after which the samples were first sieved using muslin cloth and filtrate was filtered using membrane filter of $0.45 \mu \mathrm{m}$ pore size. The filtrates were vaporized to dryness using rotary evaporator and were preserved in a sterile bottle at temperature of $4^{\circ} \mathrm{C}$ for further use [15].

\subsection{Phytochemical Screening of the Plants' Extracts}

The qualitative and quantitative phytochemical screening of the extracts were carried out using standard procedure as described by $[16,17]$.

\subsection{Reconstitution of the Methanolic, Chloroform and Water Extracts}

The crude extract of methanolic, chloroform and water leaves was reconstituted with $30 \%$ dimthylsulphoxide (DMSO) at concentration of $400 \mathrm{mg} / \mathrm{ml}$ [18]. 


\subsection{Selection of Anopheles Mosquitoes used in this Study}

The Anopheles (Anopheles gambie) mosquitoes were obtained from stagnant water using physical characteristics of the larvae for identification. They were reared and maintained at $27 \pm 3{ }^{\circ} \mathrm{C}$ and $80 \pm 10$ Relative Humidity (RH) [19]. They were reared on a diet of floating catfish feed. The adults' mosquitoes were maintained in screened cages on $10 \%$ sucrose solution for $24 \mathrm{~h}$. Repellency was tested against 3 day-old blood-starved mosquitoes, and for each test, 25 mosquitoes were used [20].

\subsection{Mosquitoes Repellency Experimental Design}

Human volunteers used in this study were students of The Federal University of Technology, Akure, Ondo State of Nigeria. The volunteers were educated about this study after seeking their verbal consent. Before the test, the skin of volunteers were washed using unscented soap and the $5.0 \mathrm{ml}$ of extract being tested was applied to the exposed part of the skin. After the application, the hand was not allowed to be rubbed, touched, or wetted. An untreated hand was used as control (Negative control) and the one with DEET was used as a standard (Positive control).

Volunteers were exposed for 5 hours (from $5 \mathrm{pm}$ to $10 \mathrm{pm}$ ) to mosquito bites. Bright torchlights were used to view the volunteers' reaction to bites. The observations were recorded at 30 minutes intervals. All experiments were run at ambient temperature $\left(27 \pm 2{ }^{\circ} \mathrm{C}\right)$ and relative humidity of $80 \pm 10 \%$. The numbers of mosquitoes landing on hand were recorded and the mean percentage protection was calculated [21]. Three replicates were run for each repellent and in each replicate different volunteer were used to nullify any effect of skin differences on repellency.

\subsection{Animal Testing}

The extracts were tested on laboratory animals. The animals were laboratory rats with average 350 to $400 \mathrm{~g}$ weight. A $4 \times 8 \mathrm{~cm}$ of animal abdomen hairs was shaved then washed and cleaned with $75 \%$ ethanol. Treatments were $5 \mathrm{ml}$ of the extracts containing $20 \%$ of active ingredients of extracts, $5 \mathrm{ml}$ of DMSO (Dimethyl sulphoxide) as Negative control and $0.5 \mathrm{ml}$ DEET (N, N-diethyl-3-methylbenzamide) in the same way were used as a positive control. After treatment, the animal was transferred into the cage in which the treated position was exposed to mosquitoes for 5 hours. Each test was repeated three times, replacing new mosquitoes and new animal and number of bites through the fabrics was recorded.

For each repellent, mosquitoes which had been starved for 24 hour were used. Percentage repellency was calculated using the method of [22] as illustrated below,

$\%$ repellency $=[(\mathrm{Nc}-\mathrm{Nt}) / \mathrm{Nc}] \times 100$

where $\mathrm{Nc}=$ is the number of mosquitoes landing on the control subject,

$\mathrm{Nt}=$ is the number of mosquitoes landing on the treated subject used in each of the experiments.

\subsection{Ethical Considerations}

Ethical permit for human volunteer assay was granted by the ethical review committee of the Federal University of Technology, Akure, Ondo State of Nigeria while the ethical permit for animal assay was granted by the animal ethical review committee, Department of Animal Production and Health, Federal University of Technology, Akure, Ondo State of Nigeria.

\section{RESULTS}

\subsection{Percentage Yield of Plant Extracts}

Table 1 shows the percentage yield of plant extracts. The methanol extract of $C$. citratus had the highest percentage yield of $10.3 \%$ while the least percentage yield was observed in the water extracts $7.2 \%$.

Table 1. Percentage yield of plant extracts.

\begin{tabular}{|c|c|c|c|}
\hline Solvent & Original weight(g) & Extracted weight(g) & 20.6 \\
\hline Methanol & 200 & 10.3 & 18.7 \\
\hline Chloroform & 200 & 14.4 & 9.35 \\
\hline Water & 200 & 7.2 \\
\hline
\end{tabular}




\subsection{Qualitative Phytochemical Result of $C$. Citratus Extracts}

The result of the qualitative phytochemical analysis of $C$. citratus extracts is showed in Table 2. The result review the presence of tannin and alkaloid in methanol, water and chloroform extract, however, steroid and anthraquinone were absent. Water extract of plant showed the presence of tannin, alkaloids, terpenoid, flavonoid, saponin and glycosides, while chloroform extract review the presence of tannin and alkaloid. Also, methanol extract and chloroform extract showed the presence of tannin, alkaloids, terpenoid and saponin.

Table 2. Results of the qualitative phytochemicals in plants' extracts.

\begin{tabular}{|c|c|c|c|}
\hline Phytochemical & CCA & CCC & CCM \\
\hline Tanin & + & + & + \\
\hline Alkaloid & + & + & + \\
\hline Terpenoid & + & - & + \\
\hline Flavonoids & + & - & - \\
\hline Saponin & + & - & + \\
\hline Glycosides & + & - & - \\
\hline Steroid & - & - & - \\
\hline Anthraquinone & - & - & - \\
\hline
\end{tabular}

Legends: $+=$ present; - =absent, $\mathrm{CCA}=$ Cymbopogon citratus aqueous extract; $\mathrm{CCC}=C$. citratus Chloroform extract; $\mathrm{CCM}=C$. citratus $\mathrm{Methanol}$ extract. Fig. (1): Percentage Phytochemical Composition of C. citratus (Lemon Grass) extract. Legends: LG (Water) = Lemon Grass Water, LG $($ Chloroform $)=$ Lemon Grass Chloroform, LG Methanol = Lemon Grass Methanol.

\subsection{Quantitative Phytochemical Result of $\boldsymbol{C}$. Citratus Extracts}

The quantitative phytochemical result showed that methanol extract has high total phenol composition of $43.81 \pm 0.15 \mathrm{ppm}$, this was closely followed by the chloroform extract. Water and methanol extract of $C$. citratus had higher composition of terpenoid with water having $25.25 \pm 0.08 \mathrm{ppm}$ and the methanol extract having $41.03 \pm 0.00 \mathrm{ppm}$.

This is shown in Figs. (1 and 2). The amount of terpenoid in chloroform extract was minute. The phytate content was also found to be higher in the chloroform extracts. The least phytochemical in all the extracts was steroid and glycosides both of which were at minute levels.

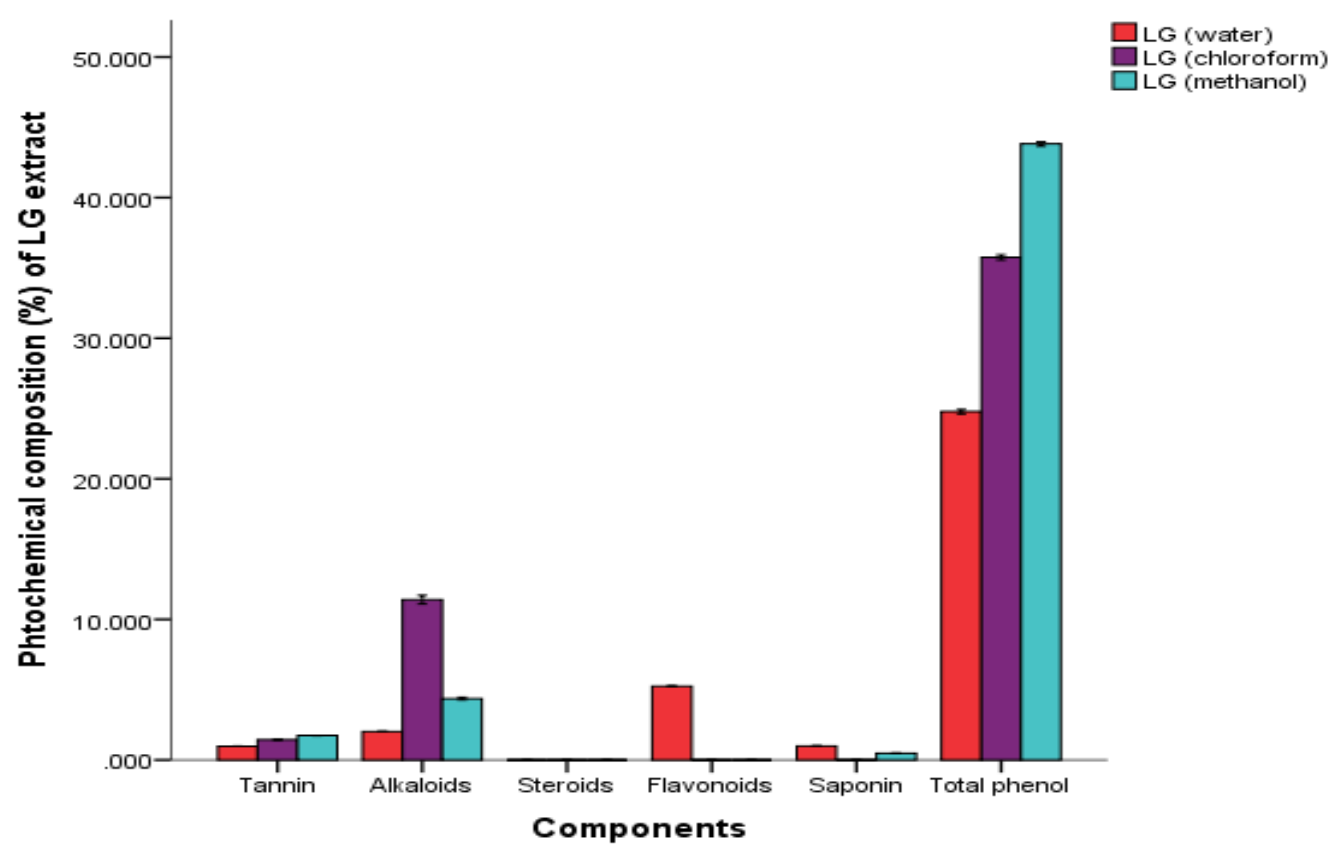

Error bars: +/- $1 \mathrm{SE}$

Fig. (1). Percentage Phytochemical Composition of C. citratus (Lemon Grass) extract.

Legends: LG $($ Water $)=$ Lemon Grass Water, LG $($ Chloroform $)=$ Lemon Grass Chloroform, LG Methanol = Lemon Grass Methanol. 


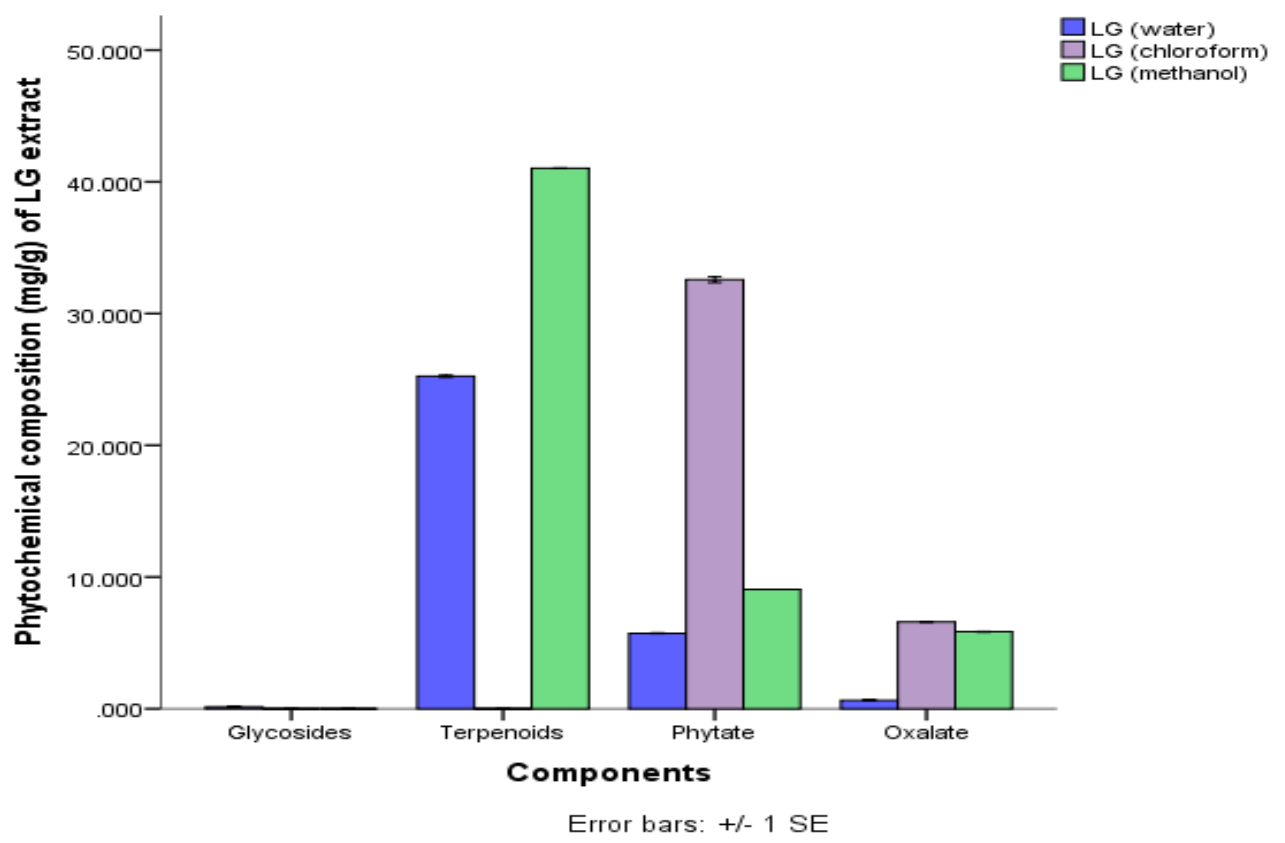

Fig. (2). Phytochemical Composition C. citratus (Lemon Grass) extract in (mg/g).

Legends: LG $($ Water $)=$ Lemon Grass Water, LG $($ Chloroform $)=$ Lemon Grass Chloroform, LG Methanol = Lemon Grass Methanol

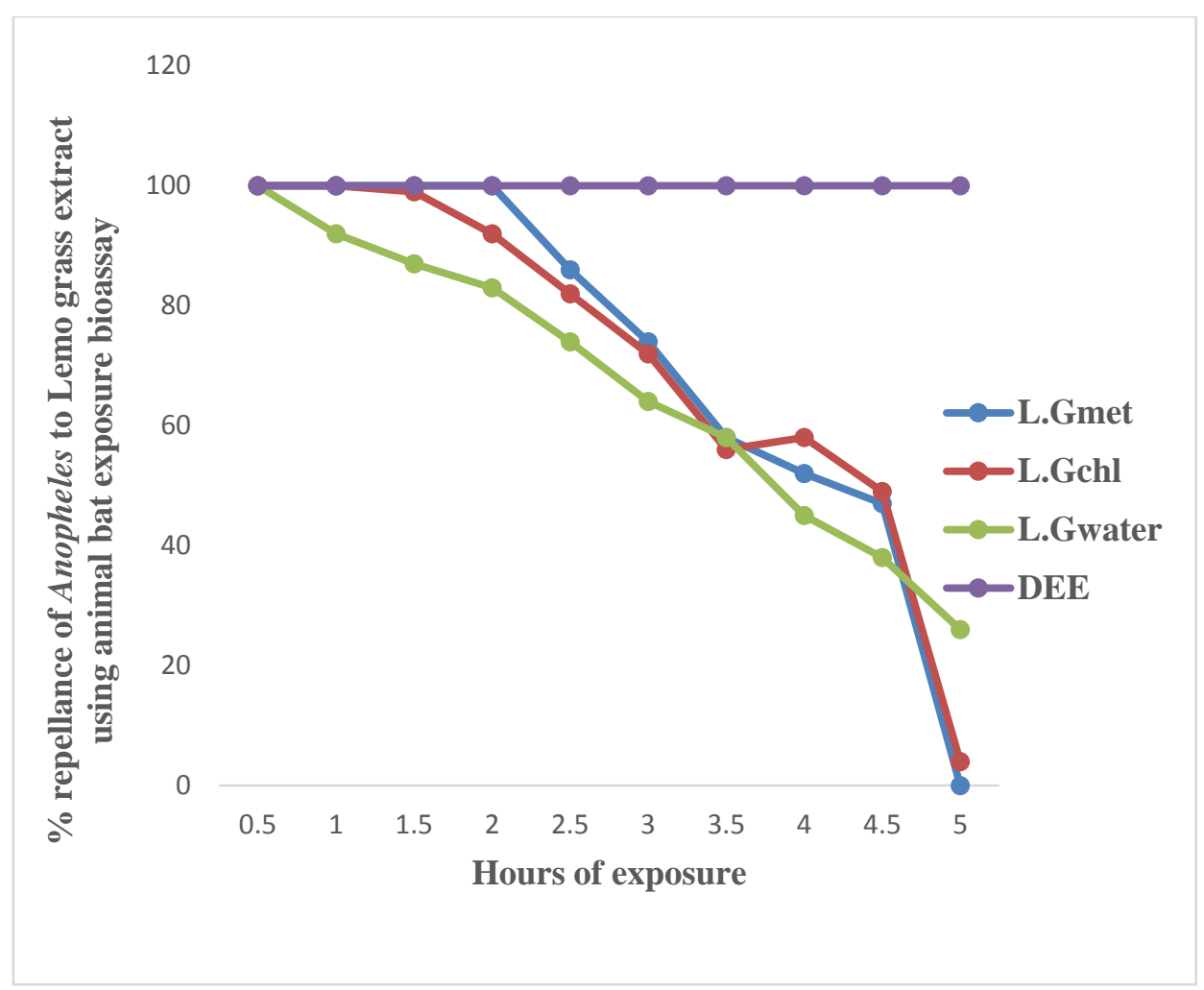

Fig. (3). Results of percentage repellent of Anopheles mosquito exposed to $400 \mathrm{mg} / \mathrm{ml}$ of C. citratus (Lemon grass) extracts using swiss albino rat.

Legends: LG Met $=$ Lemon Grass Methanol extract, LG Chl = Lemon Grass Chloroform extract, LG Water = Lemon Grass Water extract, DEET $=$ Diethyltoluamide

\subsection{Repellent Properties of Methanol, Chloroform and Water Extract of $C$. citratus}

Figs. (3 and 4) show the results of laboratory study on animals and human volunteer comparing the repellent 
properties of methanol, Chloroform and water extract of C. citratus, with the commercial insecticide (DEET) (positive control) against Anopheles mosquitoes. The result shown in Fig. (3) using experimental rat revealed that DEET had 100 percent (\%) repellency to Anopheles mosquitoes at 0.5 (30 minutes) to 5 hours, also the percentage repellency of methanol, water and chloroform extract reduces with time, water extract repellency reduce from $100 \%$ to $94 \%$ after 1 hour post application, percentage repellency of chloroform extract reduce from $100 \%$ to $94 \%$ after 2 hours post application and percentage repellency of methanol extract reduce from $100 \%$ to $83 \%$ after $2 \frac{1}{2}$ hours $(2.5)$ post application. It also revealed that percentage repellency of methanol and chloroform extracts were reduced to $0 \%$ after 5 hours post application. Fig. (4) revealed the percentage repellency of Anopheles mosquitoes exposed to C. citratus extract using human volunteers. The result showed that DEET has 100\% repellency at 0.5 (30 minutes) to 5 hours. However, percentage repellency of water extract reduced from $100 \%$ to $87 \%$ after $1 \frac{1}{2}$ hour post application, percentage repellency of chloroform reduced from $100 \%$ to $87 \%$ after $2 \frac{1}{2}$ hours post application while $\%$ percentage repellency of methanol extract reduced from $100 \%$ to $90 \%$ after 3 hours post application.

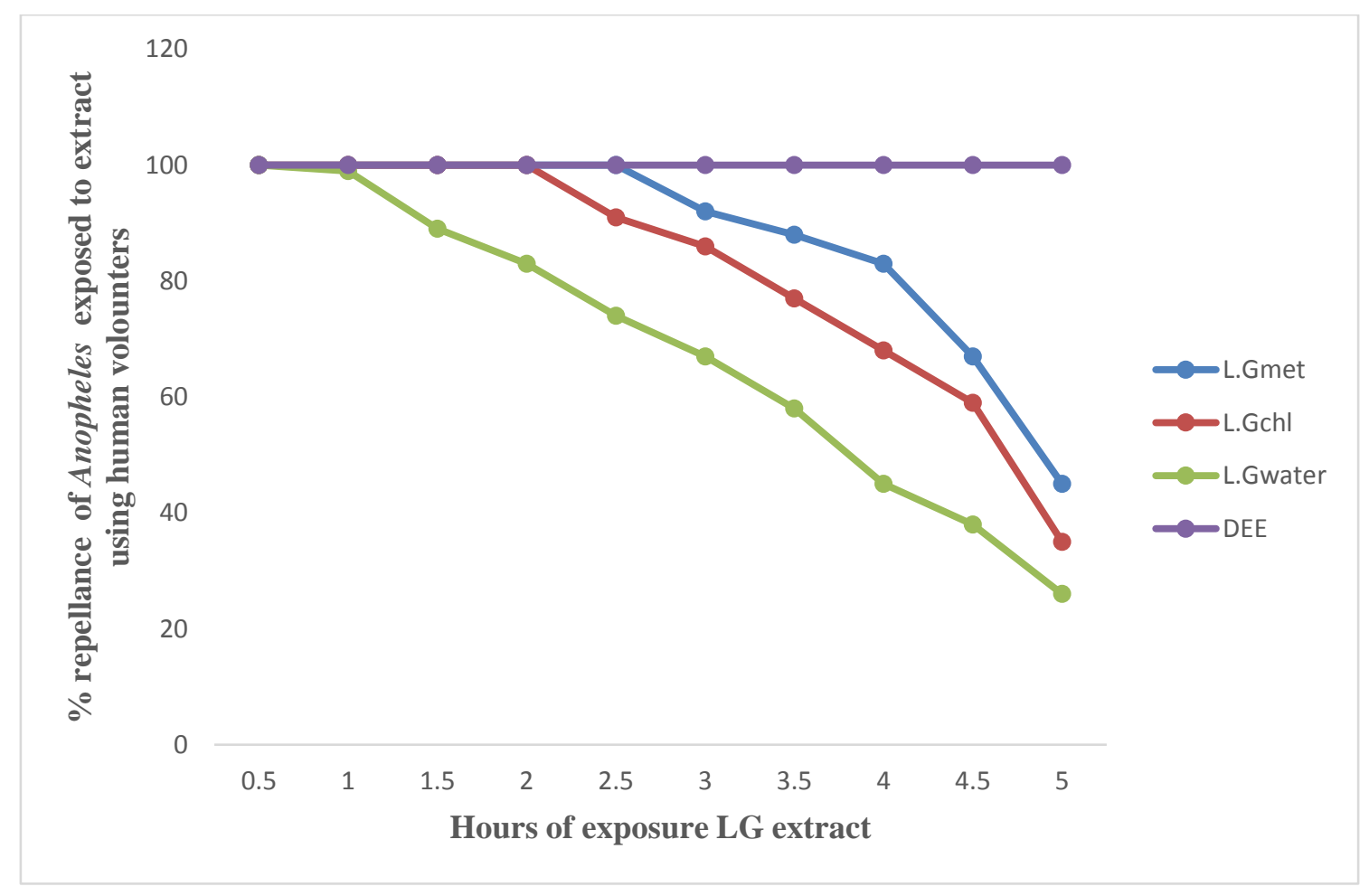

Fig. (4). Result of percentage repellent of Anopheles mosquito exposed to $400 \mathrm{mg} / \mathrm{ml}$ of C. citratus (Lemon grass) extract using human volunteers.

Legends: LG Met=Lemon Grass Methanol extract, LG Chl=Lemon Grass Chloroform extract, LG Water=Lemon Grass Water extract, DEET=Diethyltoluamide

\section{DISCUSSION}

The percentage yield of the extract from the solvent extraction showed that methanol solvent gave the highest yield. This may be due to the fact that methanol is a polar solvent and may be able to extract the active ingredients of the plant without denaturing them. This agreed with the findings of Iloki et al., [23], who reported that methanolic extracts of some certain plants contained the highest total amounts of phenolics, flavonoids and condensed tannin compounds when compared to percentage yields of the other solvent systems: (chloroform and water). The presence of phytochemicals is an indication that the plants contain bioactive component that might be responsible for the antibacterial and repellency properties of the extracts. This result is in accordance with the report of Soares et al., [24], who reported the presence of some phytochemical constituents in these plants.

Moreover, depending on the type and amount of alkaloids present in the methanolic extract, this could present some kind of toxicity that should be characterized and monitored, if necessary [24]. Total phenols are secondary metabolites found in high amount in extracts with a very low content of tannin and saponin. This agreed with the work of Iloki et 
al., [23], who reported high total phenol in C. citratus leave extract. Alkaloids are nitrogenous compounds that showed insecticidal properties at low concentration and are often toxic to vertebrates. Tepenoids are among the most widespread, structurally diverse plant produced natural pesticides. A triterpinoid obtained from the Neem tree and several monoterpenes such as citronella, pinene, linolool from essential oils are common terpenoids known to possess insecticidal activities. Generally, the monoterpenoids and sesquiterpenes are associated with repellent properties of several essential oils [25].

Methanol extract showed better repellent properties than chloroform and water extract. One major observation of the repellent properties of C. citratus is that it induces skin irritation /skin rash on the body of the shaved albino rat and the fore arm of the human volunteers. This observation agreed with the findings of Shine et al., [26], who reported on the skin irritation potential of C. citratus extract. Motoyshi et al., and Christopher et al., [27, 28], have also reported that citral, a major component of the $C$. citratus can induce skin irritation in human.

The result of the repellence potential of the extracts obtained in this study revealed that $C$. citratus extracts were $100 \%$ effective for animal bait and human volunteers for at least 2 hours post application, after which repellence fell slowly from $100 \%$. This is in accordance with the work of Oshaghi [22], which stated that $100 \%$ repellence of plantderived repellants rarely exceeds 2 hours. He also stated that plant repellence above $60 \%$ will be considered good and that below $60 \%$ will be considered poor. Amer and Melhorn [29] reported that the repellency activity of the plant extracts against mosquitoes could be due to the presence of some phytochemical constituents in the plants. Although, repellent efficacy of plant extract are generally attributed to some particular compounds but if a synergistic phenomenon established among these metabolites, then it may also result in an increased bioactivity compared to isolated components [30]. However; Adeniran and Fabiyi [14] reported that the pure lemongrass oil provided 95\% repellency for three (3) hours. The extended repellency efficacy reported by Adeniran and Fabiyi [14], compared to this study could be as a result of different repellency efficacy of essential oil and leaf extract because the main phytochemicals responsible for repellency may be concentrated in oil than leaf, also, the oil used has been purified which could also enhance the higher repellent efficacy reported.

This study also showed that the application of $C$. citratus repellent compounds gave acceptable percentage biting protection against Anopheles mosquitoes which is not significantly different $(\mathrm{P} \leq 0.05)$ from the protection seen in the commercial insecticides (DEET) used as positive control under similar conditions.

This study has shown that leaf extracts of $C$. citratus possess repellent properties against Anopheles mosquitoes. The vast and abundant phytochemical content of the extracts should be harnessed for developing and producing novel biological repellents.

\section{CONCLUSION}

The presence of bioactive component of the leaf extract suggest that this plants are physiologically active, supporting the claim by traditional healers. Isolation, identification and purification of these phytochemicals and determination of their respective potencies and toxicological evaluation with the view to formulating antibiotics should be the future direction for investigation.

\section{ETHICS APPROVAL AND CONSENT TO PARTICIPATE}

Ethical permit for human volunteer assay was granted by the ethical review committee of the Federal University of Technology, Akure, Ondo State of Nigeria while the ethical permit for animal assay was granted by the animal ethical review committee, Department of Animal Production and Health, Federal University of Technology, Akure, Ondo State of Nigeria.

\section{HUMAN AND ANIMAL RIGHTS}

All the reported experiments on humans in the study were in accordance with Parra JL, Paye m, EEMCO Group (2003) EEMCO guidance for the in vivo assessment of skin surface PH. Skin Pharmacol Appl Skin Physiol 16:188-202. And all experimentation on animals were in accordance with the Association for the Study of Animal Behavior; Animal Behavior Society 2006. Guidelines for the treatment of animals in behavioral research and teaching. Animal Behaviour, 71: 245-53. 


\section{CONSENT FOR PUBLICATION}

Written and informed consent was obtained for the study.

\section{CONFLICT OF INTEREST}

The authors declare no conflict of interest, financial or otherwise.

\section{ACKNOWLEDGEMENTS}

Declared none.

\section{REFERENCES}

[1] World Health Organization. 2010.Global information system on alcohol and health. Available from: www.who.int/globalatlas/ DataQuery/default.asp

[2] Collins WE. Plasmodium knowlesi: A malaria parasite of monkeys and humans. Annu Rev Entomol 2012; 57: 107-21. [http://dx.doi.org/10.1146/annurev-ento-121510-133540] [PMID: 22149265]

[3] Nadjm B, Behrens RH. Malaria: An update for physicians. Infect Dis Clin North Am 2012; 26(2): $243-59$. [http://dx.doi.org/10.1016/j.idc.2012.03.010] [PMID: 22632637]

[4] Owusu-Ofori AK, Parry C, Bates I. Transfusion-transmitted malaria in countries where malaria is endemic: A review of the literature from sub-Saharan Africa. Clin Infect Dis 2010; 51(10): 1192-8. [http://dx.doi.org/10.1086/656806] [PMID: 20929356]

[5] Raghavendra K, Barik TK, Reddy BP, Sharma P, Dash AP. Malaria vector control: From past to future. Parasitol Res 2011; 108(4): 757-79. [http://dx.doi.org/10.1007/s00436-010-2232-0] [PMID: 21229263]

[6] Bousema T, Okell L, Felger I, Drakeley C. Asymptomatic malaria infections: Detectability, transmissibility and public health relevance. Nat Rev Microbiol 2014; 12(12): 833-40. [http://dx.doi.org/10.1038/nrmicro3364] [PMID: 25329408]

[7] Lengeler C. Insecticide-treated bed nets and curtains for preventing malaria. Cochrane Database Syst Rev 2004; (2): CD000363. [PMID: 15106149]

[8] Mansour HA, Newairy AS, Yousef MI, Sheweita SA. Biochemical study on the effects of some egyptian herbs in alloxan-induced diabetic rats. Toxicology 2002; 170(3): 221-8. [http://dx.doi.org/10.1016/S0300-483X(01)00555-8] [PMID: 11788159]

[9] Knio KM, Usta J, Dagher S, Zournajian H, Kreydiyyeh S. Larvicidal activity of essential oils extracted from commonly used herbs in lebanon against the seaside mosquito, Ochlerotatus caspius. Bioresour Technol 2008; 99(4): 763-8. [http://dx.doi.org/10.1016/j.biortech.2007.01.026] [PMID: 17368893]

[10] Pitasawat B, Choochote W, Tuetun B, et al. Repellency of aromatic turmeric Curcuma aromatica under laboratory and field conditions. J Vector Ecol 2003; 28(2): 234-40. [PMID: 14714673]

[11] Jaenson TG, Pålsson K, Borg-Karlson AK. Evaluation of extracts and oils of mosquito (Diptera: Culicidae) repellent plants from sweden and guinea-bissau. J Med Entomol 2006; 43(1): 113-9. [http://dx.doi.org/10.1093/jmedent/43.1.113] [PMID: 16506457]

[12] Yang YC, Lee EH, Lee HS, Lee DK, Ahn YJ. Repellency of aromatic medicinal plant extracts and a steam distillate to Aedes aegypti. J Am Mosq Control Assoc 2004; 20(2): 146-9. [PMID: 15264623]

[13] Park BS, Choi WS, Kim JH, Kim KH, Lee SE. Monoterpenes from thyme (thymus vulgaris) as potential mosquito repellents. J Am Mosq Control Assoc 2005; 21(1): 80-3. [http://dx.doi.org/10.2987/8756-971X(2005)21[80:MFTTVA]2.0.CO;2] [PMID: 15825766]

[14] Adeniran OI, Fabiyi E. A cream formulation of an effective mosquito repellent: A topical product from lemongrass oil (Cymbopogon citratus) Stapf. J Nat Prod Plant Resource 2012; 2(2): 322-7.

[15] Dabur R, Ali M, Sigh H, Gupta J, Sharma G. A novel antifungal pyrole derivative from Datura metel. Pharmazie CODEN Pharlet. Afr J Microbiol Res 2004; 59(7): 568-70. [PMID: 15296098]

[16] Sofowora A. Medicinal plants and traditional medicine in africa. 3rd ed. Ibadan: Spectrum Books 2008.

[17] Ojo OO, Anibijuwon II. Studies on extracts of three medicinal plants of South- western Nigeria: Hoslundia opposita, Lantana camara and Cymbopogon citratus. Adv Nat Appl Sci 2010; 4(1): 93-8.

[18] Solomon GO, Shittu GA. In vitro antimicrobial and phytochemical activities of Acacia nilotica leaf extract. J Med Plants Res 2010; 4(12): $1232-4$. 
[19] Choochote W, Chaiyasit D, Kanjanapothi D, et al. Chemical composition and anti-mosquito potential of rhizome extract and volatile oil derived from Curcuma aromatica against aedes aegypti (Diptera: Culicidae). J Vector Ecol 2005; 30(2): $302-9$. [PMID: 16599168]

[20] Karunamoorthy K, Ilango K, Murugan K. Laboratory evaluation of traditionally used plant-based insect repellents against the malaria vector Anopheles arabiensis Patton. Parasitol Res 2010; 106(5): 1217-23. [http://dx.doi.org/10.1007/s00436-010-1797-y] [PMID: 20195634]

[21] Carroll SP, Loye J. PMD, a registered botanical mosquito repellent with deet-like efficacy. J Am Mosq Control Assoc 2006; 22(3): 507-14. [http://dx.doi.org/10.2987/8756-971X(2006)22[507:PARBMR]2.0.CO;2] [PMID: 17067054]

[22] Oshaghi MA. Repellent effects of extracts and essential oils of citrus limon (rutaceae) and melissa officinalis (labiatae) against main malaria vector anopheles stephensi (Dipteria: Culicidae). Iran J Public Health 2003; 32(4): 23-9.

[23] Iloki-Assanga SB, Lewis-Luján LM, Lara-Espinoza CL, et al. Solvent effects on phytochemical constituent profiles and antioxidant activities, using four different extraction formulations for analysis of bucida buceras L. and phoradendron californicum. BMC Res Notes 2015; 8: 396-404.

[http://dx.doi.org/10.1186/s13104-015-1388-1] [PMID: 26323940]

[24] Soares MO, Alves RC, Pires PC, Oliveira MB, Vinha AF. Angolan Cymbopogon citratus used for therapeutic benefits: Nutritional composition and influence of solvents in phytochemicals content and antioxidant activity of leaf extracts. Food Chem Toxicol 2013; 60: 413-8.

[http://dx.doi.org/10.1016/j.fct.2013.07.064] [PMID: 23911554]

[25] Olivero-Verbel J, Nerio LS, Stashenko EE. Bioactivity against tribolium castaneum herbst (Coleoptera: Tenebrionidae) of cymbopogon citratus and eucalyptus citriodora essential oils grown in colombia. Pest Manag Sci 2010; 66(6): 664-8. [PMID: 20205230]

[26] Shine JY, Park SC, Kim K, Shin D, Kim S, Kim J. Primary dermal irritation of lemon grass (cymbopogon citratus) essential oil in rabbits. J Toxicol Pub Health 2005; 21(3): 249-53.

[27] Motoyshi K, Toyoshima Y, Sato M, Yoshimura M. Comparative studies on the irritancy of oils and synthetic perfumes to the skin of rabbit, guinea pig, rat, miniature swine and man. Cosmet Toilet 2011; 94: 41-8.

[28] Christopher E, Ekpenyong EE, Akpan Nyebuk ED. Phytochemical constituents, therapeutic applications and toxicological profile of Cymbopogon citratus Staph (DC) leaf extract. Journal of Pharmacologonsy and Phytochemistry 2014; 3(1): 133-41.

[29] Amer A, Mehlhorn H. Larvicidal effects of various essential oils against aedes, anopheles, and culex larvae (Diptera, Culicidae). Parasitol Res 2006; 99(4): 466-72. [http://dx.doi.org/10.1007/s00436-006-0182-3] [PMID: 16642386]

[30] Omolo MO, Okinyo D, Ndiege IO, Lwande W, Hassanali A. Repellency of essential oils of some kenyan plants against anopheles gambiae. Phytochemistry 2004; 65(20): 2797-802.

[http://dx.doi.org/10.1016/j.phytochem.2004.08.035] [PMID: 15474566]

\section{(C) 2018 Omoya et al.}

This is an open access article distributed under the terms of the Creative Commons Attribution 4.0 International Public License (CC-BY 4.0), a copy of which is available at: https://creativecommons.org/licenses/by/4.0/legalcode. This license permits unrestricted use, distribution, and reproduction in any medium, provided the original author and source are credited. 